\title{
Hydrogen Peroxide Generation by DC and Pulsed Underwater Discharge in Air Bubbles
}

\author{
Ranhua Xiong*, Anton Nikiforov, Patrick Vanraes, and Christophe Leys \\ Research Unit Plasma Technology (RUPT), Department of Applied Physics, Ghent University, Jozef Plateaustraat \\ 22, B-900, Ghent, Belgium
}

\begin{abstract}
:
The generation of $\mathrm{H}_{2} \mathrm{O}_{2}$ in underwater discharge in air bubbles is studied with consideration of the influence of electrodes polarity, input power, solution conductivity and the inter-electrode distance. The efficiency of hydrogen peroxide generation strongly depends on the polarity, input power and the inter-electrode distance. Discharges in air bubbles with water as a cathode have significantly higher energy yield of hydrogen peroxide in comparison with negative DC or pulsed discharges. The generation of hydrogen peroxide by DC discharge increases with decrease in the inter-electrode distance, but it is opposite for pulsed discharges. Different efficiency of $\mathrm{H}_{2} \mathrm{O}_{2}$ production is explained based on physical processes which result to formation of $\mathrm{OH}$ radicals.
\end{abstract}

Keywords: Hydrogen peroxide generation; Underwater discharge; Atmospheric plasma

\section{Introduction}

Over the past years, underwater electrical discharges have received a lot of attention in view of possible applications in different fields of science and technologies such as advanced oxidation of water pollutions, sterilization, organic synthesis (1-3). Underwater discharges can be used as a source of active species $\left(\mathrm{O}_{3}, \mathrm{OH}, \mathrm{O}_{2}{ }^{*}, \mathrm{H}_{2} \mathrm{O}_{2}\right)$, ions $\left(\mathrm{H}_{3} \mathrm{O}^{+}, \mathrm{O}^{+}, \mathrm{H}^{-}, \mathrm{O}^{-}\right.$, $\left.\mathrm{OH}^{-}\right)$, UV radiation and shock wave $(4-5,39)$. It is clear that these high reactive species produced in liquid medium can be used to degrade many organic compounds, for sterilization, water purification, etc. $(6,7,40)$. There are a lot of methods by which underwater plasma can be generated and sustained. In general, underwater discharges can be divided into three main groups based on the physics of underwater breakdown (8). Streamer/spark discharges in a gas and liquid medium are always generated by high voltage pulsed with duration from a few nanoseconds to microseconds with the current up to some kA (43). The second group of underwater discharges is diaphragm or capillary discharge where two reservoirs filled with a conductive liquid are separated by a dielectric barrier in which a current pathway (diaphragm) is made between two reservoirs or water streamers $(16,37)$. The plasma is formed in the pathway by AC or DC high voltage across the reservoirs. The third group is electrical discharges in gas or vapor bubbles or on the water surface $(18,41,42)$. Different kinds of experimental setups developed for discharge in gas or vapor bubbles were summarized in a recently published

*Corresponding author; E-mail: Ranhua.Xiong@UGent.be review article (9). One of the types is a discharge in bubbles which are produced by external gas flow through a glass tube in which a metal high voltage electrode is inserted. This type of reactor with artificially produced bubbles has an advantage of significantly reducing of the input power because of absence of Joule heating of liquid medium. Additionally, this discharge can be initiated by DC voltage with much lower voltage compared to direct liquid phase discharge (10-11). Reducing the rate of erosion of electrode is another advantage of this type of reactor. Presence of plasma/liquid interface allows initiating of a wide range of chemical reactions in gas phase as well as in a liquid medium. Most of the researcher revealed direct correlation of plasma-liquid treatment efficiency (purification, sterilization, etc.) with amount of $\mathrm{H}_{2} \mathrm{O}_{2}$ produced by plasma. Hydrogen peroxide formation by means of plasma is useful indicator for commercial applications in chemical, environmental and disinfection processes (14-15). A recent review (13) on hydrogen peroxide formation in electrical discharge plasma with liquid water shows major factors affecting hydrogen peroxide formation in gas and liquid. Among of them are: UV radiation, temperature, ozone, $\mathrm{pH}$, solution conductivity, salt type and electrode materials.

The present study is focused on the hydrogen peroxide formation in DC and pulsed discharge and on the effect of input power, solution conductivity, inter-electrode distance and water polarity on hydrogen peroxide formation. In order to estimate the efficiency of hydrogen peroxide formation by the reactor, the energy yield and generation rate of hydrogen peroxide are compared with literature. 

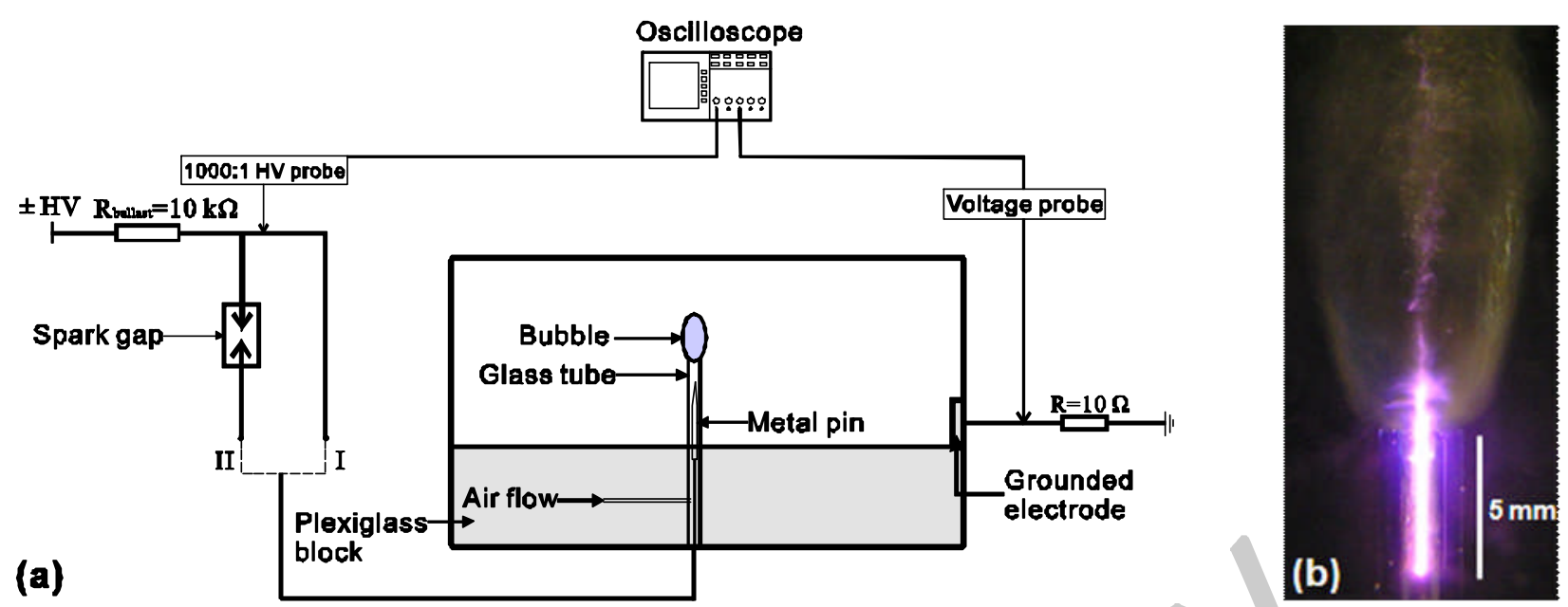

Figure 1. (a) Experimental set-up: underwater discharge in air bubbles generated by DC (I) or pulsed voltage(II); (b) an image of positive DC discharge plasma with the inter-electrode distance $\mathrm{d}=5 \mathrm{~mm}$, current $\mathrm{I}=30 \mathrm{~mA}$, solution conductivity $\sigma=250 \mu \mathrm{S} / \mathrm{cm}$.

\section{Experimental Set-up}

The scheme of the reactor is shown in Figure 1. The discharge is generated in the air bubbles between a metal pin positioned inside of glass tube and the water surface. In present study positive and negative DC power supply and pulsed generator have been used in order to generate plasma. The DC discharge is excited by positive or negative voltage through a ballast resister $(10 \mathrm{k} \Omega)$ in the range of $1-3 \mathrm{kV}$ and current of $10-40$ $\mathrm{mA}$. The pulsed discharge is produced by means of self triggered spark gap stabilized by fast gas flow. Air flow applied for stabilization of the pulsed generator is used furthermore for bubbles production by subdivision of air flow into 14 channels. Each tube is connected to a glass tube at one side of the Plexiglass block used as a reactor vessel. The metal needle-pins inside of the glass tubes at the bottom of vessel play the role of a high-voltage electrode. The distance from the tip of pin to the orifice of glass tube is adjustable. The distance is also regarded as inter-electrode distance. It has to be noted that although the reactor can sustain plasma in 14 independent channels at average current of $30 \mathrm{~mA}$ in pulsed mode, only one channel is used in case of DC mode because of current limitation of the power supply. The grounded electrode is a metal tube placed at one side of the vessel as shown in Figure 1. All experiments are carried out in a solution of $\mathrm{NaH}_{2} \mathrm{PO}_{4} \cdot 2 \mathrm{H}_{2} \mathrm{O}$ with initial conductivity 50 or 1500 $\mu \mathrm{S} / \mathrm{cm}$. Tektronix P6015A 1000:1 high voltage probe is used to measure the applied voltage waveform. The solution conductivity in the vessel is measured by Consort C533 meter.

The concentration of hydrogen peroxide in the liquid produced by the discharge is determined with a photometric method using the reactions of $\mathrm{H}_{2} \mathrm{O}_{2}$ with metavanadate ammonium as explained in detail in
(17). Used method has almost the same sensitivity and selectivity to $\mathrm{H}_{2} \mathrm{O}_{2}$ as a reaction with titanium (IV) oxalate (30) and an advantage of long life time of reagents. The statistic error of measurement is estimated about $5 \%$ for $\mathrm{H}_{2} \mathrm{O}_{2}$ concentration higher than $5 \mathrm{mmol} / \mathrm{L}$ and $10 \%$ for lower concentration (19).

\section{Results and Discussion}

\section{Electrical Properties of DC and Pulsed Discharge}

Voltage/current (V/C) characteristics of DC discharge and typical current-voltage waveforms of pulsed discharge in bubbles are presented in Figure 2. Figure 2 (a) is corresponding to the positive DC discharge at $2 \mathrm{~mm}$ inter-electrode, $50 \mu \mathrm{s} / \mathrm{cm}$ initial conductivity. Visual appearance and V/C characteristics of DC discharge are similar to one investigated by Bruggeman P. et al (31) whereas the pulsed mode of the discharge has not been used and reported before. It has to be noted that in the present work we do not provide more details on physical properties of the discharge like $n_{e}$, $T_{e}$, spectral characteristics because of our focus on estimation of chemical efficiency of the plasma and the very complex relation between plasma properties and rate of $\mathrm{H}_{2} \mathrm{O}_{2}$ production. The power of DC and pulsed discharge is defined as follow and is used furthermore for estimation of hydrogen peroxide yield:

$$
P=\bar{U} \bar{I} \quad P=\frac{1}{\Delta T} \int_{T}^{T+\Delta T} U(t) I(t) d t
$$

where $\overline{\mathbf{U}}, \quad \overline{\mathbf{I}}$ are average voltage, current of DC discharge and $\mathbf{U}(\mathbf{t}), \quad \mathbf{I}(\mathbf{t})$ are voltage and current during time of $\boldsymbol{\Delta} \mathbf{T}$ for pulsed discharge. 

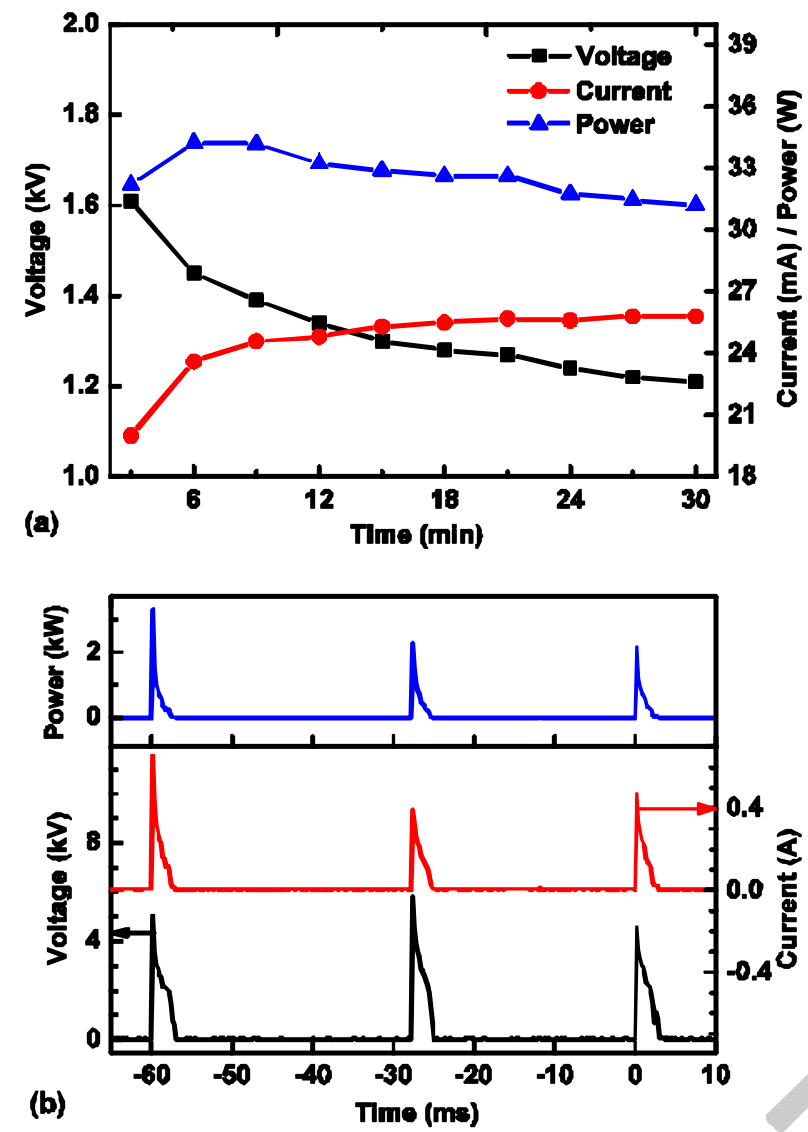

Figure 2. Voltage, current and power characteristics of positive DC discharge (a) and voltage-current waveform of positive pulsed discharge (b) at inter-electrode distance $\mathrm{d}=2 \mathrm{~mm}$ and initial conductivity $\sigma=50 \mu \mathrm{S} / \mathrm{cm}$.

During DC operation the average voltage decreases from $1.61 \mathrm{kV}$ at beginning to $1.22 \mathrm{kV}$ after $30 \mathrm{~min}$, and the average current increases from $20 \mathrm{~mA}$ to 26 $\mathrm{mA}$ while the power is nearly constant at $32 \mathrm{~W}$ as shown in Figure 2 (a). The negative DC discharge has similar electric features. The main reason is the increase of solution conductivity from $50 \mu \mathrm{S} / \mathrm{cm}$ to $1100 \mu \mathrm{S} / \mathrm{cm}$ after $30 \mathrm{~min}$ due to the formation of $\mathrm{HNO}_{3}$ in solution under plasma action (20). The voltage change can be explained by the change in the equivalent resistance of the water electrode with time. The equivalent resistance is nearly $10 \mathrm{k} \Omega$ in initial water with conductivity of $\sigma=50 \mu \mathrm{S} / \mathrm{cm}$, while it is only several hundreds $\Omega$ at the end of the experiment for the conductivity of $1 \mathrm{mS} / \mathrm{cm}$ and so the corresponding voltage drop changes from hundreds volt to several volts. Figure 2 (b) represents the positive pulsed discharge voltage and current waveform. Although the conductivity increased approximately to $330 \mu \mathrm{S} / \mathrm{cm}$, the pulsed discharge is unaffected by conductivity change like DC discharge. The increase of the discharge current (peak value) in pulsed mode from $0.6 \mathrm{~A}$ to $0.65 \mathrm{~A}$ is observed after 30 minutes of discharge operation which results to slight increasing the discharge power on $7-10 \%$ at the end of the experiments. No difference in shape of current or voltage pulses has been observed in pulsed plasma due to change of the solution conductivity.

\section{Hydrogen Perxiode Generation with Different Polarity and Conductivity}

Hydrogen peroxide is generated in reactor in a large number of reactions $(5,14,16)$. Reduced set of reactions of $\mathrm{H}_{2} \mathrm{O}_{2}$ formation and destruction on the basis of the literature data is presented in Table 1.

The $\mathrm{H}_{2} \mathrm{O}_{2}$ generation by other particles such as $\mathrm{OH}, \mathrm{H}^{+}, \mathrm{HO}_{2}$, and $\mathrm{O}^{*-}$ is negligible in the view of their low concentration in the solution and there are not presented in Table $1(27,38)$. Based on results of some recent calculations (13) and investigations of mechanisms of (27) underwater discharge chemical efficiency, the main $\mathrm{H}_{2} \mathrm{O}_{2}$ production path is generation from $\mathrm{OH}$ radicals in dimerization reaction - Table 1 reaction 3. Because of key role of $\mathrm{OH}$ radical in the plasma chemistry of the underwater plasma in air bubbles the set of reactions of $\mathrm{OH}$ radical production can be written as (with $\mathrm{k}$ in $\mathrm{cm}^{3} \mathrm{~s}^{-1}$ ):

\section{Electron collisions}

$$
\begin{aligned}
& \mathrm{e}+\mathrm{H}_{2} \mathrm{O} \rightarrow \mathrm{OH}+\mathrm{H}+\mathrm{e} \\
& \mathrm{k}=2.3 \times 10^{-12}-1.8 \times 10^{-10} \quad T_{\mathrm{e}}=1-2 \mathrm{eV} \\
& \mathrm{e}+\mathrm{H}_{3} \mathrm{O}^{+} \rightarrow \mathrm{OH}+\mathrm{H}_{2}+\mathrm{e} \\
& \mathrm{k}=10^{-6} \quad T_{\mathrm{e}}=1 \mathrm{eV} \\
& \mathrm{k}=4.9 \times 10^{-12}-4.7 \times 10^{-11} \quad T_{\mathrm{e}}=1-2 \mathrm{eV}
\end{aligned}
$$

\section{Ion collisions}

$$
\mathrm{H}_{2} \mathrm{O}^{+}+\mathrm{H}_{2} \mathrm{O} \rightarrow \mathrm{OH}+\mathrm{H}_{3} \mathrm{O}^{+} \quad \mathrm{k}=1.9 \times 10^{-9}
$$

Dissociation by radicals and metastables

$$
\begin{aligned}
& \mathrm{N}_{2}(\mathrm{~A})+\mathrm{H}_{2} \mathrm{O} \rightarrow \mathrm{OH}+\mathrm{N}_{2}(\mathrm{X})+\mathrm{H} \\
& \mathrm{k}=6 \times 10^{-14} \quad T_{\mathrm{g}} \approx 300 \mathrm{~K} \\
& \mathrm{~N}\left({ }^{2} \mathrm{D}\right)+\mathrm{H}_{2} \mathrm{O} \rightarrow \mathrm{OH}+\mathrm{NH} \\
& \mathrm{k}=2.5 \times 10^{-10} \quad T_{\mathrm{g}} \approx 300 \mathrm{~K} \\
& \mathrm{O}\left({ }^{1} \mathrm{D}\right)+\mathrm{H}_{2} \mathrm{O} \rightarrow \mathrm{OH}+\mathrm{OH} \\
& \mathrm{k}=2.2 \times 10^{-10} \quad T_{\mathrm{g}} \approx 300 \mathrm{~K} \\
& \mathrm{O}+\mathrm{H}_{2} \rightarrow \mathrm{OH}+\mathrm{H} \\
& \mathrm{k}=9.3 \times 10^{-18}-5.7 \times 10^{-11} \quad T \mathrm{~g}=300-3000 \mathrm{~K} \\
& \mathrm{H}+\mathrm{O}_{2} \rightarrow \mathrm{OH}+\mathrm{O} \\
& \mathrm{k}=2.5 \times 10^{-21}-1.3 \times 10^{-11} \quad T_{\mathrm{g}}=300-3000 \mathrm{~K}
\end{aligned}
$$

Vibrational collisions

$$
\begin{gathered}
\mathrm{H}_{2} \mathrm{O}+\mathrm{H}_{2} \mathrm{O}^{*} \rightarrow \mathrm{OH}+\mathrm{H}+\mathrm{H}_{2} \mathrm{O} \\
\mathrm{k}=10^{-14} \quad T_{\mathrm{v}}=0.5 \mathrm{eV} \quad T_{\mathrm{g}}=300 \mathrm{~K}
\end{gathered}
$$


Table 1. Rate of reactions of $\mathrm{H}_{2} \mathrm{O}_{2}$ formation and destruction under plasma action in $\mathrm{cm}^{3} \mathrm{~s}^{-1}$ for two-body reactions and $\mathrm{cm}^{6} \mathrm{~s}^{-1}$ for threebody reactions.

\begin{tabular}{|c|c|c|c|}
\hline $\mathrm{N}$ & Reaction & Typical rate & Reference \\
\hline 1 & $\mathrm{HO}_{2}+\mathrm{HO}_{2} \rightarrow \mathrm{H}_{2} \mathrm{O}_{2}+\mathrm{O}_{2}$ & $2.2 \times 10^{-13} \mathrm{e}^{600 / \mathrm{T}}$ & [33] \\
\hline 2 & $\mathrm{HO}_{2}+\mathrm{HO}_{2}+\mathrm{M} \rightarrow \mathrm{H}_{2} \mathrm{O}_{2}+\mathrm{O}_{2}+\mathrm{M}$ & $1.9 \times 10^{-33} \mathrm{e}^{980 / \mathrm{T}}$ & [33] \\
\hline 3 & $\mathrm{OH}+\mathrm{OH}+\mathrm{M} \rightarrow \mathrm{H}_{2} \mathrm{O}_{2}+\mathrm{M}$ & $2.6 \times 10^{-11}$ at $298 \mathrm{~K}$ & [33] \\
\hline 4 & $\mathrm{H}_{2} \mathrm{O}_{2}+\mathrm{O} \rightarrow \mathrm{HO}_{2}+\mathrm{OH}$ & $1.4 \times 10^{-12} \mathrm{e}^{-2000 / T}$ & [33] \\
\hline 5 & $\mathrm{H}_{2} \mathrm{O}_{2}+\mathrm{OH} \rightarrow \mathrm{HO}_{2}+\mathrm{H}_{2} \mathrm{O}$ & $2.9 \times 10^{-12} \mathrm{e}^{-160 / T}$ & [33] \\
\hline 6 & $\mathrm{H}_{2} \mathrm{O}_{2}+\mathrm{e} \rightarrow \mathrm{OH}+\mathrm{OH}+\mathrm{e}$ & $2.36 \times 10^{-9}$ & [32] \\
\hline 7 & $\mathrm{H}_{2} \mathrm{O}_{2}+\mathrm{e} \rightarrow \mathrm{H}+\mathrm{HO}_{2}+\mathrm{e}$ & $3.1 \times 10^{-11}$ & [27] \\
\hline 8 & $\mathrm{H}_{2} \mathrm{O}_{2}+\mathrm{H} \rightarrow \mathrm{H}_{2}+\mathrm{HO}_{2}$ & $8.0 \times 10^{-11} \exp \left(-4000 / T_{\mathrm{g}}\right)$ & [27] \\
\hline 9 & $\mathrm{H}_{2} \mathrm{O}_{2}+\mathrm{H} \rightarrow \mathrm{H}_{2} \mathrm{O}+\mathrm{OH}$ & $4.0 \times 10^{-11} \exp \left(-2000 / T_{\mathrm{g}}\right)$ & [27] \\
\hline 10 & $\mathrm{H}_{2} \mathrm{O}_{2} \rightarrow 2 \mathrm{OH}$ & $2 \times 10^{9} T_{g}^{-4.86} \exp \left(-26821 / T_{\mathrm{g}}\right)$ & [27] \\
\hline
\end{tabular}

Table 2. Rate of reactions of $\mathrm{OH}$ destruction and quenching in presence of $\mathrm{N}_{2}$ and $\mathrm{O}_{2}$.

\begin{tabular}{|c|c|c|c|}
\hline $\mathrm{N}$ & Reaction & Typical rate $\left(\mathrm{cm}^{3} \mathrm{~s}^{-1}\right)$ & Reference \\
\hline 1 & $2 \mathrm{OH} \rightarrow \mathrm{O}+\mathrm{H}_{2} \mathrm{O}$ & $1.8 \times 10^{-12}$ & {$[36]$} \\
\hline 2 & $\mathrm{OH}+\mathrm{H}_{2} \rightarrow \mathrm{H}+\mathrm{H}_{2} \mathrm{O}$ & $7.7 \times 10^{-12} \exp \left(-2100 \times 8.6 \times 10^{-5} / T_{\mathrm{g}}\right)$ & [36] \\
\hline 3 & $\mathrm{OH}+\mathrm{O} \rightarrow \mathrm{H}+\mathrm{O}_{2}$ & $2.3 \times 10^{-11} \exp \left(-110 \times 8.6 \times 10^{-5} / T_{\mathrm{g}}\right)$ & {$[36]$} \\
\hline 4 & $\mathrm{OH}+\mathrm{O} \rightarrow \mathrm{HO}_{2}$ & $2.1 \times 10^{-10}$ & {$[32]$} \\
\hline 5 & $\mathrm{OH}+\mathrm{O}_{3} \rightarrow \mathrm{HO}_{2}+\mathrm{O}_{2}$ & $1.9 \times 10^{-12} \exp \left(-1000 \times 8.6 \times 10^{-5} / T_{\mathrm{g}}\right)$ & [32] \\
\hline 6 & $\mathrm{OH}+\mathrm{H} \rightarrow \mathrm{H}_{2} \mathrm{O}$ & $2 \times 10^{-10}$ & [34] \\
\hline 7 & $\mathrm{OH}+\mathrm{HO}_{2} \rightarrow \mathrm{H}_{2} \mathrm{O}+\mathrm{O}_{2}$ & $1.1 \times 10^{-10}$ & {$[28]$} \\
\hline 8 & $\mathrm{OH}+\mathrm{N} \rightarrow \mathrm{O}+\mathrm{NH}$ & $4.7 \times 10^{-11}$ & [34] \\
\hline 9 & $\mathrm{OH}+\mathrm{NH} \rightarrow \mathrm{NO}+\mathrm{H}_{2}$ & $8 \times 10^{-11}$ & [34] \\
\hline 10 & $\mathrm{OH}+\mathrm{HNO} \rightarrow \mathrm{NO}+\mathrm{H}_{2} \mathrm{O}$ & $1.5 \times 10^{-11}$ & [34] \\
\hline 11 & $\mathrm{OH}+\mathrm{NO}+\mathrm{M} \rightarrow \mathrm{HNO}_{2}+\mathrm{M}$ & $3.3 \times 10^{-11}$ & [34] \\
\hline 13 & $\mathrm{OH}+\mathrm{NO}_{2}+\mathrm{M} \rightarrow \mathrm{HNO}_{3}+\mathrm{M}$ & $7.5 \times 10^{-11}$ & [34] \\
\hline
\end{tabular}

Thermal dissociation starts to play an important role if $\mathrm{T}_{\mathrm{g}}$ higher than $2500 \mathrm{~K}$ that can be realized e.g. in cathode area of the discharge:

$$
\begin{aligned}
& \mathrm{H}_{2} \mathrm{O}+\mathrm{H}_{2} \mathrm{O} \rightarrow \mathrm{OH}+\mathrm{H}+\mathrm{H}_{2} \mathrm{O} \\
& \mathrm{k}=10^{-20}-4 \times 10^{-14} \mathrm{~cm}^{3} \mathrm{~s}^{-1} \quad T \mathrm{~g}=2500-5000 \mathrm{~K}
\end{aligned}
$$

The set of reactions of $\mathrm{OH}$ destruction is presented in Table 2. In order to take in to account effect of air in our system some important reactions including nitrogen chemistry are included in Table 2 as well. Generation of plasma in air buubles leads to generation of ground state $\mathrm{OH}$ in reactions of $\mathrm{H}_{2} \mathrm{O}$ dissociation as shown above with rate constant as high as $2.5 \times 10^{-10} \mathrm{~cm}^{3} \mathrm{~s}^{-1}$, but on the other hand $\mathrm{OH}$ radicals effectively reacts with nitrogen oxides $\mathrm{NO}$ and $\mathrm{NO}_{2}$, Table 2 reactions $10-11$, as well as with $\mathrm{NH}, \mathrm{HNO}$ and N. From technological point of view it is important to mention that sustainment of the discharge in air bubbles leads to acidification of the solution due to formation of $\mathrm{HNO}_{3}$.

The global kinetic of hydrogen peroxide production and decomposition can be assumed to follow zeroorder kinetics at initial time at shown on Figure 3 and can be describe as :

$$
\frac{\mathrm{d}\left[\mathrm{H}_{2} \mathrm{O}_{2}\right]}{\mathrm{dt}}=\mathrm{k}_{1}-\mathrm{k}_{2}(\mathrm{~T})\left[\mathrm{H}_{2} \mathrm{O}_{2}\right]
$$

where $\left[\mathrm{H}_{2} \mathrm{O}_{2}\right]$ is the hydrogen peroxide molar concentration, $\mathrm{k}_{1}$ is the $\mathrm{H}_{2} \mathrm{O}_{2}$ production rate constant, $\mathrm{k}_{2}$ is the decomposition rate constant. The main reaction leading to the formation of $\mathrm{H}_{2} \mathrm{O}_{2}$ by discharge in air bubbles is dimerization of $\mathrm{OH}$ radical whereas decomposition is mainly due to thermal destruction as follows $(20,26)$ :

$\mathrm{H}_{2} \mathrm{O}_{2} \stackrel{\mathrm{K}_{2}(\mathrm{~T})}{\longrightarrow} \mathrm{H}_{2} \mathrm{O}+\frac{1}{2} \mathrm{O}_{2}$ 


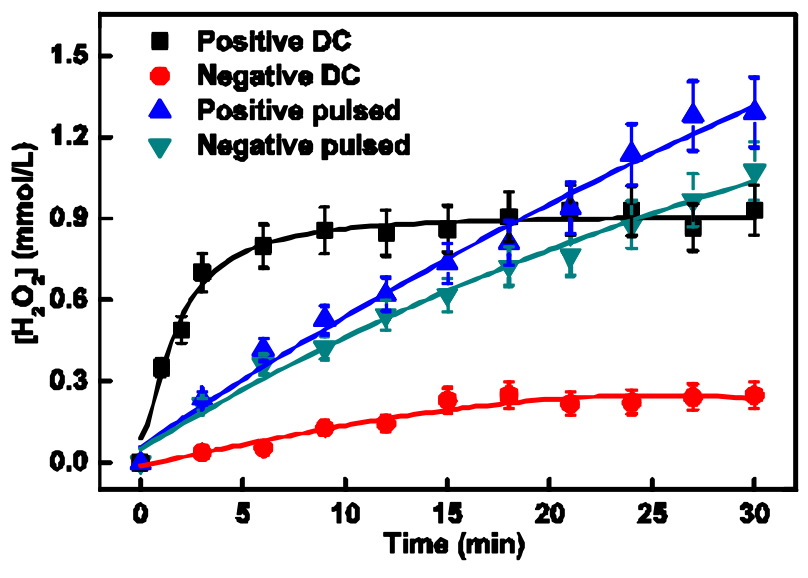

Figure 3. Hydrogen peroxide generation with time by positive, negative $\mathrm{DC}(\mathrm{P}=45 \mathrm{~W} \mathrm{~d}=2 \mathrm{~mm}, \sigma=50 \mu \mathrm{S} / \mathrm{cm})$ and pulsed discharge $(\mathrm{P}=40 \mathrm{~W}, \mathrm{~d}=2 \mathrm{~mm}, \sigma=50 \mu \mathrm{S} / \mathrm{cm})$.

Figure 3. shows experimental results on the $\mathrm{H}_{2} \mathrm{O}_{2}$ generation over time by positive, negative $\mathrm{DC}$ and pulsed discharge in air bubbles. The $\mathrm{H}_{2} \mathrm{O}_{2}$ generation by positive DC discharge (water as cathode) reaches a steady-state condition after about $300 \mathrm{~s}$ as shown in Figure 3 at a $\mathrm{H}_{2} \mathrm{O}_{2}$ concentration of $0.7 \mathrm{mmol} / \mathrm{L}$. At steady-state regime observed in experiemts, the rate of $\mathrm{H}_{2} \mathrm{O}_{2}$ destruction (depending on $\mathrm{k}_{2}$ ) is equal to the rate of formation (depending on $\mathrm{k}_{1}$ ) which means that thermal destruction of $\mathrm{H}_{2} \mathrm{O}_{2}$ plays an important role in DC mode. For negative DC discharge (water as anode), the $\mathrm{H}_{2} \mathrm{O}_{2}$ concentration is much lower, not more than $0.2 \mathrm{mmol} / \mathrm{L}$ after 30 minutes of the discharge. Similar results on influence of polarity has been mentioned in (20). The $\mathrm{H}_{2} \mathrm{O}_{2}$ concentration linearly increases over time during $27 \mathrm{~min}$ and then reaches a steady-state mode on time scale of 60-70 minuts for pulsed discharges. The $\mathrm{H}_{2} \mathrm{O}_{2}$ generation rate of positive pulsed discharge is slightly higher by comparsion with negative pulsed discharge.

According to our experimental results the solution conductivity has a negligible influence on $\mathrm{H}_{2} \mathrm{O}_{2}$ formation where the reason is that the discharge within bubbles in liquid is generated in a gas phase and mechanism of $\mathrm{H}_{2} \mathrm{O}_{2}$ generation is not effected by solution conductivity.

\section{Hydrogen Peroxide Generation with Different Input Power and Different Inter-electrode Distance}

Kinetic plots of the $\mathrm{H}_{2} \mathrm{O}_{2}$ concentration for different input power at fixed inter-electrode distance of $2 \mathrm{~mm}$ and initial conductivity of $50 \mu \mathrm{s} / \mathrm{cm}$ are presented in Figure 4(a) for positve DC discharge and figure 4(b) for negative pulsed discharge. Increase of the input power in pulsed discharge results in the growing of
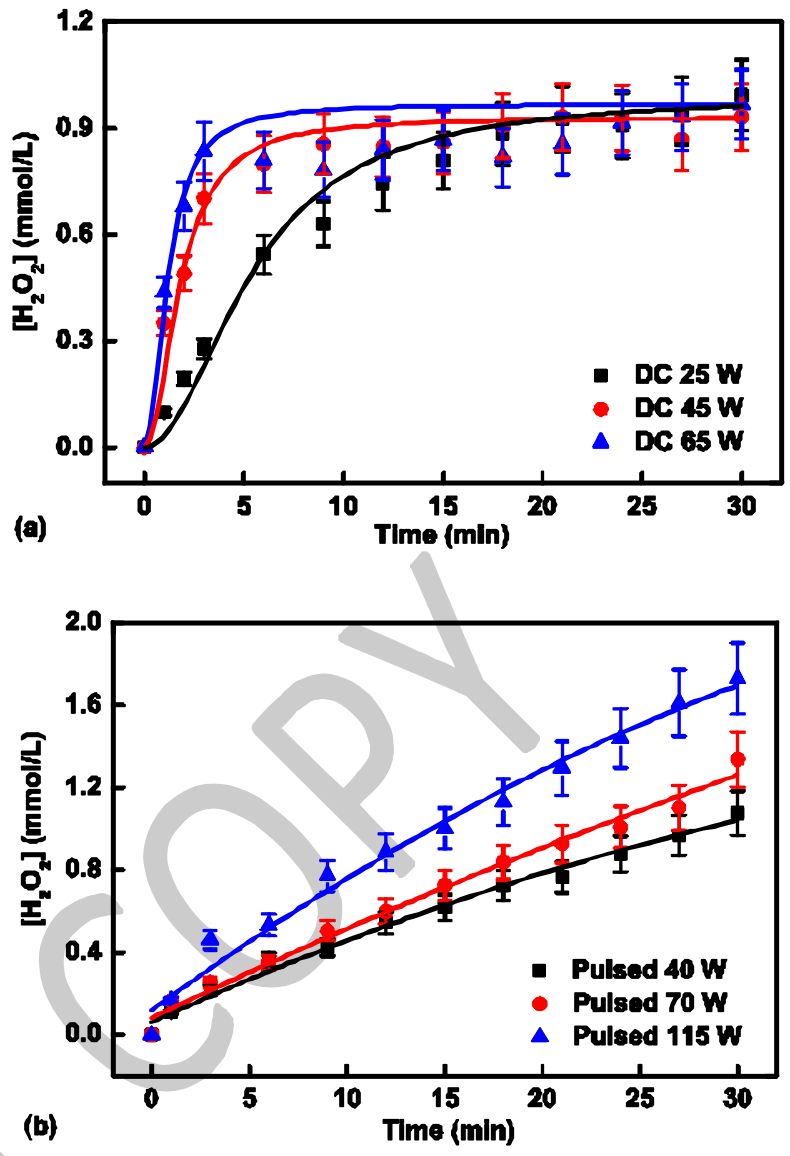

Figure 4. Hydrogen peroxide generation with time by positive DC ((a) $\sigma=50 \mu \mathrm{S} / \mathrm{cm}, d=2 \mathrm{~mm}$ ) and negative pulsed ((b) $\sigma=50 \mu \mathrm{S} / \mathrm{cm}$, $\mathrm{d}=2 \mathrm{~mm}$ ) discharge with different power.

$\mathrm{H}_{2} \mathrm{O}_{2}$ concentration with almost linear dependence on input power. Whereas an increase of the input power from 25 to $65 \mathrm{~W}$ of DC discharge leads to almost the same steady-state concentration of $\mathrm{H}_{2} \mathrm{O}_{2}$ but the initial slope of the kinetic plots has a strong dependence on input power. Probably the main explanation is the thermal destruction of $\mathrm{H}_{2} \mathrm{O}_{2}$ in case of DC discharge where gas temperature directly depends on the input power (8-9). In order to take into account the process of $\mathrm{H}_{2} \mathrm{O}_{2}$ destruction, it is necessary to calculate the energy yield of $\mathrm{H}_{2} \mathrm{O}_{2}$ formation to estimate the efficiency of $\mathrm{H}_{2} \mathrm{O}_{2}$ generation. The $\mathrm{H}_{2} \mathrm{O}_{2}$ formation energy yield has been calculated from initial formation rate as (16):

$h_{\mathrm{H} 202}=\left.\frac{\mathrm{dC}_{\mathrm{H}_{2} \mathrm{O}_{2}}}{\mathrm{dt}}\right|_{\mathrm{t}-0} \cdot\left(\mathrm{t}_{2}-\mathrm{t}_{1}\right) \cdot \operatorname{Mr}\left(\mathrm{H}_{2} \mathrm{O}_{2}\right) \mathrm{P}^{-1}$

where $\mathrm{t}_{2}-\mathrm{t}_{1}=3600 \mathrm{~s}, \mathrm{Mr}\left(\mathrm{H}_{2} \mathrm{O}_{2}\right)$ is the molecular mass of $\mathrm{H}_{2} \mathrm{O}_{2}, \mathrm{P}$ (defined in (1)) is the power of the discharge, $\mathrm{dC}_{\mathrm{H}_{2} \mathrm{O}} /\left.\mathrm{dtt}\right|_{\mathrm{t} \rightarrow 0}$ is the initial rate of $\mathrm{H}_{2} \mathrm{O}_{2}$ formation, which can be calculated from the slope of the initial linear section of the kinetic curves. 


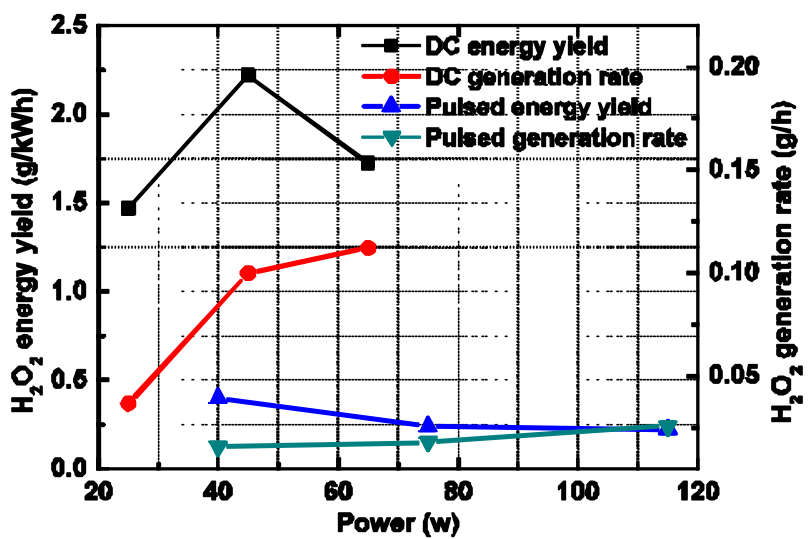

Figure 5. Hydrogen peroxide energy yield and generation rate with different power for positive DC and negative pulsed discharge corresponding to Figure 4 (a) and (b).

Figure 5 shows the $\mathrm{H}_{2} \mathrm{O}_{2}$ energy yield and generation rate at different power of DC and pulsed discharge. Although the $\mathrm{H}_{2} \mathrm{O}_{2}$ generation rates increase with higher power, the $\mathrm{H}_{2} \mathrm{O}_{2}$ energy yields have different characteristics. It can be seen from Figure 5 that the $\mathrm{H}_{2} \mathrm{O}_{2}$ energy yield of DC discharge goes through a maximum $(2.22 \mathrm{~g} / \mathrm{kWh})$, after which, with a further increase in power, starts to decrease. On the other hand, the energy yield of pulsed discharges is almost constant at different power and much smaller than one for DC dischagre.

Another important parameter of the plasma/liquid system is the inter-electrode distance, which has strong influence on $\mathrm{H}_{2} \mathrm{O}_{2}$ production $(12,22,23)$. Figure 6 shows the production of hydrogen peroxide by DC (a) and pulsed (b) discharges at different interelectrode distances. The kinetic plots of hydrogen peroxide generation in DC discharge follow equation [8] with high $\mathrm{k}_{2}(\mathrm{~T})$ at 2 and $4 \mathrm{~mm}$ inter-electrode distance. During the first phase (the first $3 \mathrm{~min}$ discharge as shown in Figure 6 (a)), the hydrogen peroxide concentration is nearly linear increase with time at different inter-electrode distance. After the first $3 \mathrm{~min}$, the hydrogen peroxide concentration increases with a lower rate by comparison with the first phase at inter-electrode distance of $1 \mathrm{~mm}$, while it reaches a steady-state at the inter-electrode distance of $2 \mathrm{~mm}$. $\mathrm{H}_{2} \mathrm{O}_{2}$ concentration almost linearly decreases with time after first phase when the inter-electrode distance is set as $4 \mathrm{~mm}$. An explanation of the effect is the thermal destruction of $\mathrm{H}_{2} \mathrm{O}_{2}$ in the water near the airwater interface. Estimation of the gas temperature from emission of the $\mathrm{N}_{2}$ band (not shown here) gives gas temperature about $2300 \pm 150 \mathrm{~K}$ for $1 \mathrm{~mm}$ distance and $3500 \pm 150 \mathrm{~K}$ for $4 \mathrm{~mm}$ distance. Validity of used method for gas temperature measurements has been proved by numerous works; see e.g. (8) and references
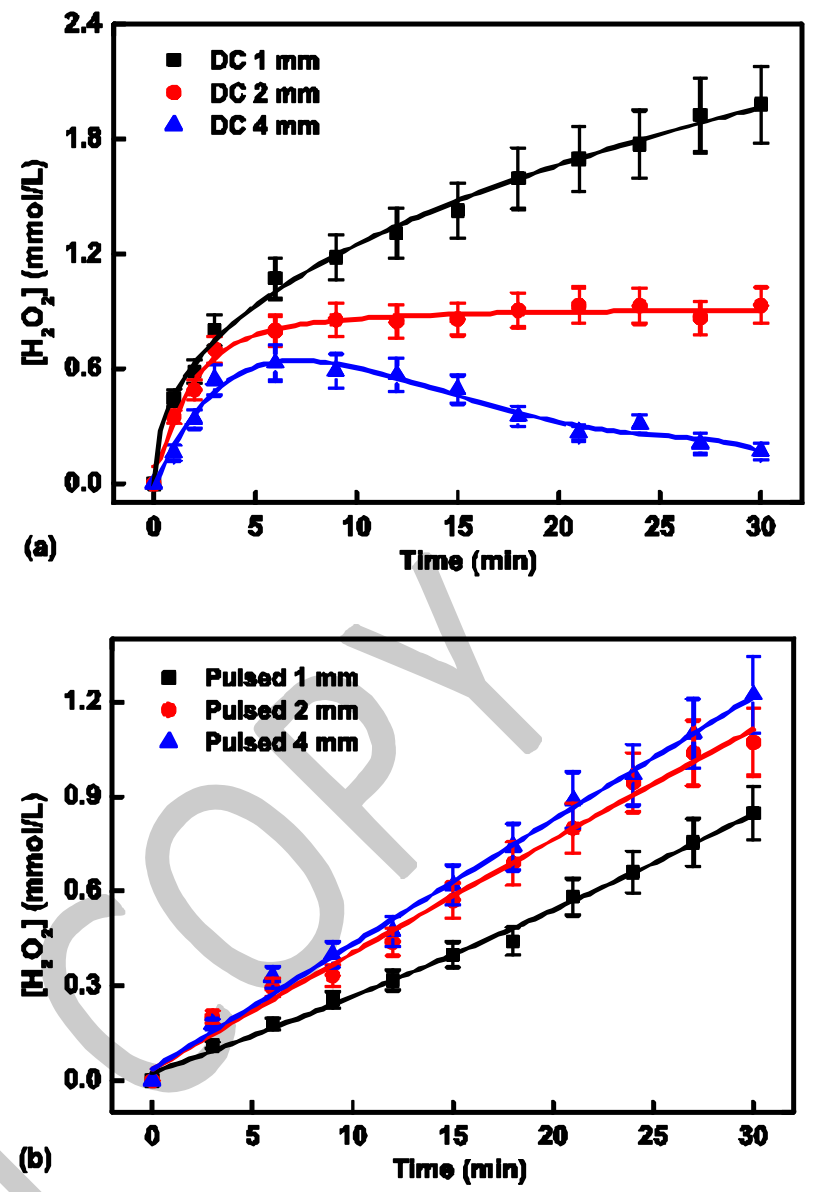

Figure 6. Hydrogen peroxide generation with time by positive DC $(\mathrm{P}=45 \mathrm{~W}, \sigma=50 \mu \mathrm{S} / \mathrm{cm})$ and negative pulsed discharge $(\mathrm{P}=65 \mathrm{~W}$, $\sigma=50 \mu \mathrm{S} / \mathrm{cm}$ ) at different inter-electrode distance.

herein. Because of the increasing residence time and gas temperature with increase of the inter-electrode distance, more energy transfers to the bulk water in the vicinity of the air-water interface during plasma operation. This leads to almost linear increase of liquid medium temperature with increase of the electrode gap. On the contrary with DC discharge, the hydrogen peroxide generation rate increases with increasing inter-electrode distance in the case of pulsed discharge which is characterized by a much lower gas temperature around $1500 \pm 150 \mathrm{~K}$ not depending on the gap size.

In view of applications it is worthwhile comparing different types of discharge based on the efficiency of the hydrogen peroxide formation. The data of the maximum energy yield are listed in Table 3. It has to note that the energy yield values in case of pulsed mode are almost independent on the applied voltage. In case of interest to other plasma/liquid systems we would like to refer readers to the recent review by $\mathrm{B}$. Locke (13) where extensive comparison of different systems is presented. 
Table 3. Hydrogen peroxide generation energy yields and generation rate by using negative, positive DC and pulsed power.

\begin{tabular}{cccc}
\hline $\begin{array}{c}\text { Discharge mode } \\
\text { and polarity }\end{array}$ & $\begin{array}{c}\text { Input power } \\
\text { (W) }\end{array}$ & $\begin{array}{c}\text { Energy } \\
\text { yield } \\
(\mathrm{g} / \mathrm{kWh})\end{array}$ & $\begin{array}{c}\text { Generation } \\
\text { rate }(\mathrm{g} / \mathrm{h})\end{array}$ \\
\hline Positive DC & 45 & 2.30 & $1.04 \mathrm{E}-1$ \\
Negative DC & 45 & 0.22 & $9.79 \mathrm{E}-3$ \\
Positive Pulsed & 40 & 0.60 & $2.50 \mathrm{E}-2$ \\
Negative Pulsed & 40 & 0.40 & $1.59 \mathrm{E}-2$ \\
\hline
\end{tabular}

It can be stated, based on the presented results, that the $\mathrm{H}_{2} \mathrm{O}_{2}$ energy yield is higher when water is a cathode. As discussed previously, the main reaction of $\mathrm{H}_{2} \mathrm{O}_{2}$ generation is dimerization of solvated $\mathrm{OH}$ radicals in liquid phase - Table 1, reaction [3]. $\mathrm{OH}$ radical is produced under plasma action in a wide set of processes but furthermore it effectively reacts with $\mathrm{H}_{2} \mathrm{O}, \mathrm{N}_{2}$ and $\mathrm{O}_{2}$, etc. see e.g. (27-28). Characteristic life time of $\mathrm{OH}$ radical because of quenching and its high reactivity is in the order of $10^{-7} \mathrm{~s}$ which means that only $\mathrm{OH}$ radicals produced on the plasma/liquid interface with $\mu \mathrm{m}$ thickness can reach the liquid, be solvated and take a part in Table 1, reaction [3]. This condition is realized in streamer pulsed discharge (4-5) with duration of exciting pulse up to $10^{-6} \mathrm{~s}$ produced directly in liquid and in the cathode or anode layer of DC glow discharge in gas bubbles (29). In case of glow discharge, the density of $\mathrm{OH}$ radicals is higher in the cathode layer (water as a cathode) than in anode region (water as a anode) because of much higher input energy dissipated in the former $\left(I_{\text {discharge }}{ }^{*}\right.$ cathode fall), high density of water vapor by compare with gas phase and high gas temperature around 5000-7000 K where water thermal dissociation starts to play important role in $\mathrm{OH}$ production $(8,31)$. It is found that the hydrogen peroxide energy yield by positive DC discharges in air bubbles is nearly two times higher than the values reported for DC discharges in liquid and for discharges over the liquid (13). The reasons of low efficiency of pulsed system used in present work are considerably long duration of pulses and streamer mode of the discharge in gas phase. Pulsed plasma shows the absence of a glow structure and no distinguishable cathode region responsible for $\mathrm{OH}$ production. Correspondingly, only very few $\mathrm{OH}$ radicals produced in gas phase can reach liquid phase that explains so low yield of $\mathrm{H}_{2} \mathrm{O}_{2}$ in pulsed plasma here and from similar system used by other groups $(12,25)$.

\section{Conclusion}

Chemical efficiency of underwater DC and pulsed discharges in air bubbles is characterized by measure- ment of $\mathrm{H}_{2} \mathrm{O}_{2}$ production. The effect of polarity, input power, solution conductivity and the inter-electrode distance is investigated and discussed for both discharge configurations. Discharge with water as a cathode is much more effective for $\mathrm{H}_{2} \mathrm{O}_{2}$ production. The energy yield of hydrogen peroxide in DC positive discharge is as high as $2.30 \mathrm{~g} / \mathrm{kWh}$ but only $0.22 \mathrm{~g} / \mathrm{kWh}$ for negative DC discharge. The highest hydrogen peroxide energy yield in case of pulsed discharge is only $0.4 \mathrm{~g} / \mathrm{kWh}$, and input power has negligible influence on it. With comparison of hydrogen peroxide energy yield of present reactor and literature data, it is found that the discharge in air bubbles sustained by positive DC power has the highest efficiency because of presence of the cathode region where effective formation of $\mathrm{OH}$ radicals takes place.

\section{Acknowledgment}

This work is supported by China Scholarship Council (CSC) and by the Interuniversity Attraction Poles Program of the Belgian Science Policy (Project "PSI" - P6/08).

\section{References}

(1) Hayashi, D.; Hoeben, W.; Dooms, G.; van Veldhuizen, E.M.; Rutgers, W.R.; Kroesen, G.M.W. Journal of Physics D-Applied Physics 2000, 33, 2769-2774.

(2) Malik, M.A.; Ubaid ur, R.; Ghaffar, A.; Ahmed, K. Plasma Sources Science \& Technology 2002, 11, 236-240.

(3) Gao, J.Z.; Liu, Y.J.; Yang, W.; Pu, L.M.; Yu, J.; Lu, Q.F. Plasma Sources Science \& Technology 2003, 12, 533-538.

(4) Sunka, P. Physics of Plasmas 2001, 8, 2587-2594.

(5) Malik, M.A.; Ghaffar, A.; Malik, S.A. Plasma Sources Science \& Technology 2001, 10, 82-91.

(6) Abou-Ghazala, A.; Katsuki, S.; Schoenbach, K.H.; Dobbs, F.C.; Moreira, K.R. IEEE Transactions on Plasma Science 2002, 30, 1449-1453.

(7) Sato, M.; Ohgiyama, T.; Clements, J.S. IEEE Transactions on Industry Applications 1996, 32, 106-112.

(8) Bruggeman, P. PhD thesis of Ghent University, 2009, p6, 149-151.

(9) Bruggeman, P.; Leys, C. Journal of Physics DApplied Physics 2009, 42, 053001.

(10) Korobeinikov, S.M.; Melekhov, A.V.; Besov, A.S. High Temperature 2002, 40, 652-659.

(11) Miichi, T. ; Ihara, S.; Satoh, S.; Yamabe, C.; Vacuum 2000, 59, 236-243.

(12) Kai-Yuan, S.; Locke, B.R. Plasma Chemistry and Plasma Processing 2010, 30, 1-20.

(13) Locke, B.R.; Shih, K.Y. Plasma Sources Science \& Technology 2011, 20, 15. 
(14) Grymonpre, D.R.; Sharma, A.K.; Finney, W.C.; Locke, B.R. Chem. Eng. J. 2001, 82, 189-207.

(15) Mededovic, S.; Locke, B.R. Applied Catalysis BEnvironmental 2006, 67, 149-159.

(16) Nikiforov, A.Y.; Leys, C. Plasma Sources Science \& Technology 2007, 16, 273-280.

(17) Nogueira, R.F.P.; Oliveira, M.C.; Paterlini, W.C. Talanta 2005, 66, 86-91.

(18) Nikiforov, A.Y.; Leys, C.; Li, L.; Nemcova, L.; Krema, F. Plasma Sources, Science and Technology 2011, 034008 (034010 pp.).

(19) Nemcova, L.; Nikiforov, A.; Leys, C.; Krcma, F. IEEE Transactions on Plasma Science 2011, 39, 865-870.

(20) Mededovic, S.; Takashima, K.; Mizuno, A. Plasma Chemistry and Plasma Processing 2009, 29, 455-473.

(21) Shih, K.-Y.; Locke, B.R. IEEE Transactions on Plasma Science 2011; 39, 883-892.

(22) Bruggeman, P.; Jingjing, L.; Degroote, J.; Kong, M.G.; Vierendeels, J.; Leys, C. Journal of Physics D: Applied Physics 2008, 215201 (215211 pp.).

(23) Bruggeman, P.; Leys, C.; Degroote, J.; Vierendeels, J. In IEEE 35th International Conference on Plasma Science, 2008.

(24) Wang, L. Plasma Chemistry and Plasma Processing 2009, 29, 241-250.

(25) Aristova, N.A.; Piskarev, I.M.; Ivanovskii, A.V.; Selemir, V.D.; Spirov, G.M.; Shlepkin, S.I. Russian Journal of Physical Chemistry 2004, 78, 1144-1148.

(26) Takagi, J.; Ishigure, K. Nuclear Science and Engineering 1985, 89, 177-186.

(27) Liu, D.X.; Bruggeman, P.; Iza, F.; Rong, M.Z.; Kong, M.G. Plasma Sources Science \& Technology $2010,19$.

(28) Bruggeman, P.; Schram, D.C. Plasma Sources Science \& Technology 2010, 19.

(29) Verreycken, T.; Schram, D.C.; Leys, C.; Bruggeman, P. Plasma Sources Science \& Technology 2010, 19, 9.
(30) Sellers R.M. Analyst 1980, 105, 950-954.

(31) Bruggeman, P.; Schram, D.; Gonzalez, M.A.; Rego, R.; Kong, M.G; Leys, C. Plasma Sources Science \& Technology 2009, 18, 2.

(32) Soloshenko, I.A; Tsiolko, V.V.; Pogulay, S.S.; Kalyuzhnaya, A.G.; Bazhenov, V.Y.; Shchedrin, A.I. Plasma Sources Sci. Technol. 2009, 18, 045019.

(33) Atkinson, R.; Baulch, D.L.; Cox, R.A.; Crowley, J.N.; Hampson, R.F.; Hynes, R.G.; Jenkin, M.E.; Rossi, M. ; Troe, J. Atmos. Chem. Phys. 2004, 4, $1461-738$

(34) NIST Chemical Kinetics Database, Standard Reference Database 17, Version 7.0 (Web Version), Release 1.4.2, Data Version 2009.01 (http://kinetics.nist.gov/kinetics/).

(35) Fridman, A; Plasma Chemistry (Cambridge: Cambridge University Press), 2008.

(36) Baulch, D.L.; Cox, R.A.; Hampson, R.F.; Kerr, J.A.; True, J.; Watson, R.T. J. Phys. Chem. Ref. Data 1980, 9, 295.

(37) Andre, P., et al. Journal of Physics D-Applied Physics 2001, 34(24), 3456-3465.

(38) Bruggeman, P., et al. Journal of Physics D-Applied Physics 2010, 43(1), 6.

(39) Mededovic, S.; Locke, B.R Journal of Physics D Applied Physics 2007, 40(24), 7734-7746.

(40) Mededovic, S.; Locke, B.R. Industrial \& Engineering Chemistry Research 2007, 46(9), 27022709.

(41) XinPei, L.; Laroussi, M. Journal of Physics D (Applied Physics), 2003, 36(6).

(42) XinPei, L.; Leipold, F.; Laroussi, M. Journal of Physics D (Applied Physics), 2003, 36(21).

(43) Xinpei, L., et al., Journal of Applied Physics 2002, 91(1).

Received for review October 22, 2011. Revised manuscript received December 19, 2011. Accepted December 29, 2011. 